\title{
Excision of Large Pediatric Supratentorial Choroid Plexus Tumors by Endoscope-Assisted Microsurgery
}

\author{
MOHAMED GABR, M.D. and HASHEM MOHAMED ABOUL-ELA, M.D.
}

The Department of Neurosurgery, Faculty of Medicine, Cairo University

\begin{abstract}
Background: Intraventricular tumors (IVTs) are commoner in children than in adults. They represent a technical challenge during microsurgery in children due to their large size, deep location, and propensity for bleeding.
\end{abstract}

Aim of Study: We study the value of using endoscopeassistance in surgery of large choroid plexus tumors (CPTs) in children.

Patients and Methods: Pediatric patients with large CPTs were studied retrospectively from 2015-2019. Transcortical microsurgery was performed using various approaches. The endoscope was used to inspect the tumor and its pedicle. After excision, it was reintroduced to search for any missed parts and to aid in hemostasis.

Results: The study included 11 patients. Eight patients $(72.73 \%)$ presented with manifestations of increased intracranial pressure. Three patients $(27.27 \%)$ presented with hemiparesis. Only 2 patients needed permanent CSF diversion. Blood transfusion was required in some patients: $300 \mathrm{cc}$ in 6 patients, $200 \mathrm{cc}$ in 4 patients, and $150 \mathrm{cc}$ in 2 patients. The pathology results were papilloma in 6 patients, atypical papilloma in 1 patient, and carcinoma in 4 patients. Gross total resection was achieved in 9 cases. Subtotal resection was found in 2 cases. Follow-up MRI after 3 months, 2 and 4 years showed a stationary course. Transient hemiparesis was present in 2 cases and improved with physiotherapy. We did not witness mortality.

Conclusion: Endoscope-assisted microsurgery permits safe and efficient excision of large CPTs in children. It aids in complete excision which may improve survival and may avoid permanent CSF diversion.

Key Words: Large pediatric supratentorial-Choroid plexus tumors - Endoscope-assisted microsurgery.

\section{Introduction}

INTRAVENTRICULAR tumors represent less than $1 \%$ of intracranial neoplasms. However, they are more common in children approaching $5 \%$.

Correspondence to: Dr. Mohamed Gabr, The Department of Neurosurgery, Faculty of Medicine, Cairo University
Some IVTs are aggressive malignant lesions such as Choroid plexus carcinomas (CPC). However, most of these tumors are benign such as Choroid plexus papillomas (CPP) and may be cured by total excision. Owing to their slow growth rate, they may be asymptomatic and reach a big size before being detected, making surgery difficult. Usually, these lesions present with symptoms of increased ICP caused by hydrocephalus. Before the closure of the fontanelles, there may be an increasein head circumference, irritability, or poor feeding. In older children, there may be headaches or vomiting. There may be specific neurological signs based on the site of the lesion. The site of the tumor, age, and radiological findings help establish the differential diagnosis [1,2]

Microsurgical resection has been the gold standard for most of these tumors. Several tools help in surgery such as stereotactic navigational systems and minimally invasive neuroendoscopic techniques [3-6]. However, IVTs in children usually reach a substantial size at presentation which may cause dangerous bleeding during piecemeal excision, thus limiting the role of pure neuroendoscopic excision. In this study, we present our experience with endoscope-assisted microsurgery in large pediatric choroid plexus tumors (CPTs) regarding procedure and outcome.

\section{Patients and Methods}

After approval from the Institutional Review Board, this retrospective study was conducted on patients with large CPTs in the pediatric age group operated upon by surgical excision in the period between 2015-2019 in Cairo University Hospitals. A tumor was defined as large when its size exceeded $3 \mathrm{~cm}$ in its longest diameter [7-9]. All patients were subjected to complete history taking and full clinical 
examination. Radiological assessment was performed by CT brain and MRI brain with contrast. Full laboratory investigations were obtained for surgical preparation. Parenteral ceftriaxone was given according to body weight as a prophylactic antibiotic on induction of anesthesia after performing an allergy test. This antibiotic was continued for 2 days after surgery.

All patients were operated via a transcortical approach. The surgery in all cases was done by endoscope-assisted microscopic surgery. This method is well defined in the literature [10,11]. After craniotomy, corticectomy, and entering the ventricle microscopically, we introduced the endoscope to inspect the tumor and search for a possible vascular pedicle as in choroid plexus papilloma. We used rigid endoscopy in all cases "Gaab system, Karl Storz Gmbh and Co., Tuttlingen, Germany". The operating microscope was then reintroduced to secure the pedicle micro surgically. In case the pedicle was obscured by the tumor, the assistant would hold the endoscope to visualize the pedicle, while the surgeon would secure the pedicle using the microsurgical instruments (Fig. 2). Tumor debulking and removal were performed using suction and bipolar electrocautery with irrigation (Fig. 3 ). To avoid excessive or hidden bleeding from large vascular tumors, we used cottonoids to fill the space formed after piecemeal excision. The size of the cottonoid was gradually increased to fill the large space.

After the tumor mass was grossly removed, the endoscope was introduced again to check the corners around the tumor searching for any residual or a hidden bleeding source that could not be visualized except by different angled scopes.

An external ventricular catheter's tip was inserted near the foramen of Monro. The dura was sutured, the bone was repositioned, and the wound was closed in layers. Follow-up MRI scans were done 3 months and 1 year after surgery.

\section{Results}

\section{Population:}

The study included 11 patients: 5 males $(45.45 \%)$ and 6 females (54.54\%). The age of the patients ranged between 2 years and 8 years with a mean age of 4.23 years.

\section{Clinical picture:}

Eight patients (72.73\%) presented with symptoms and signs of increased intracranial pressure (headache, vomiting, and papilledema). Three patients $(27.27 \%)$ presented with hemiparesis. Other symptoms included seizures, ataxic gait, dysphasia, and facial nerve palsy.

\section{Operative methods and findings:}

Four cases were approached by temporal corticectomy, 6 cases by parietal corticectomy, and one case by middle frontal gyrus corticectomy. After completing microscopic excision in 8 cases; a small residual was visualized by the endoscope. This required further excision under vision by the endoscope.

Eight patients were hydrocephalic preoperatively. An external ventricular drain was placed intraoperatively in all cases. Six patients were successfully weaned. Only 2 patients needed a permanent VP shunt.

Blood transfusion was required in some patients, which was equivalent to $300 \mathrm{cc}$ in 5 patients, $200 \mathrm{cc}$ in 4 patients, and $150 \mathrm{cc}$ in 2 patients. The pathology results were CPP in 6 patients, atypical papilloma in 1 patient, and $\mathrm{CPC}$ in 4 patients.

\section{Outcome:}

Gross Total resection was achieved in 9 cases. A small residual was found in 2 cases, which were CPC and CPP, respectively. Follow-up MRI done after 3 months, 2 and 4 years showed a stable size. This malignant CPC patient as well as the other 3 patients in the study received chemotherapy and radiotherapy (Fig. 1).

Subdural hygroma was found in 6 patients, which was managed conservatively. One case has a postoperative seizure, which was managed by levetiracetam. Transient postoperative hemiparesis was present in 2 cases and was managed conservatively. They regained full motor power after 3 months of physiotherapy. There were no cases of mortality (Tables 1,2). 

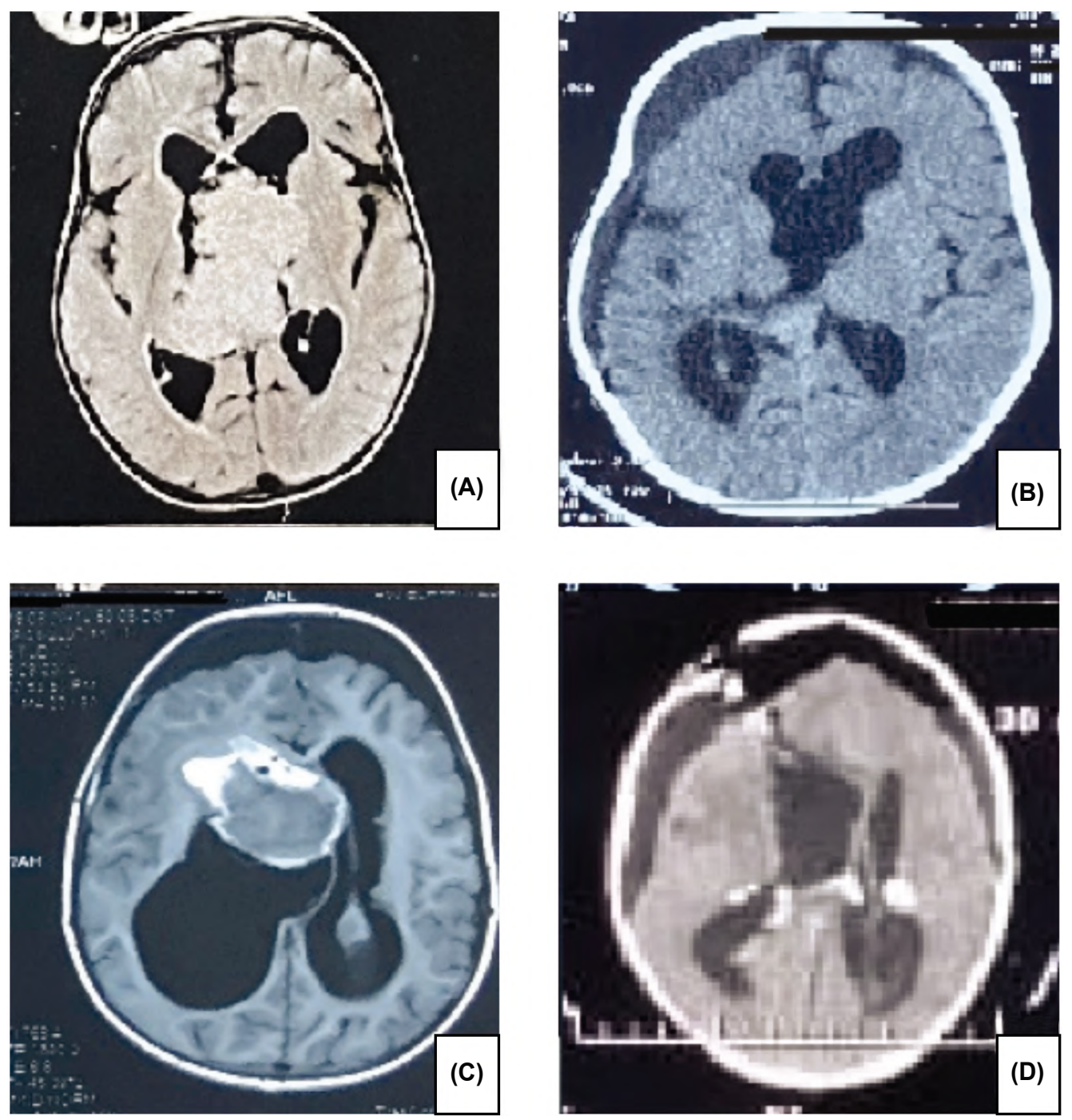

Fig. (1): (A): MRI image axial of a 2-year-old male infant with CPP operated by endoscope-assisted microsurgery. (B): Postoperative CT scan of the same patient showing a small residual which was managed conservatively. (C): MRI image axial with contrast of a 3-year-old female with CPC. (D): Postoperative scan of the same patient showing complete excision.

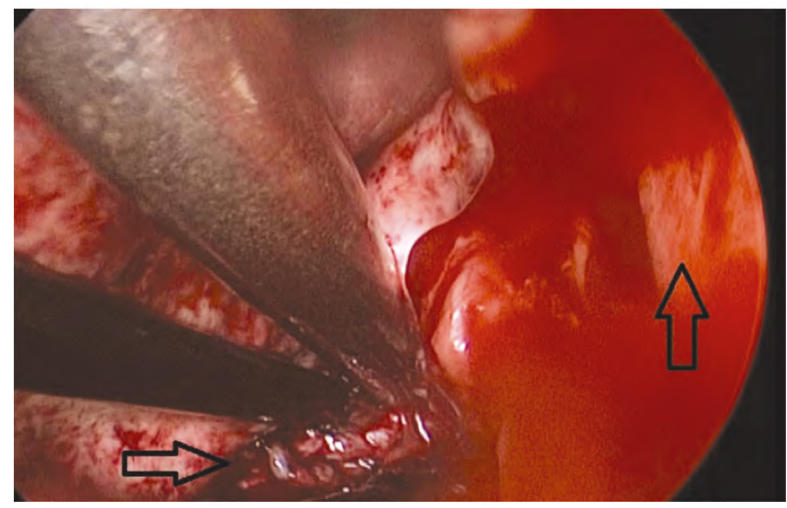

Fig. (2): Endoscope-assisted microsurgery. The Left arrow points at the pedicle being coagulated by the bipolar forceps. The Right arrow points at the tumor (CPP).

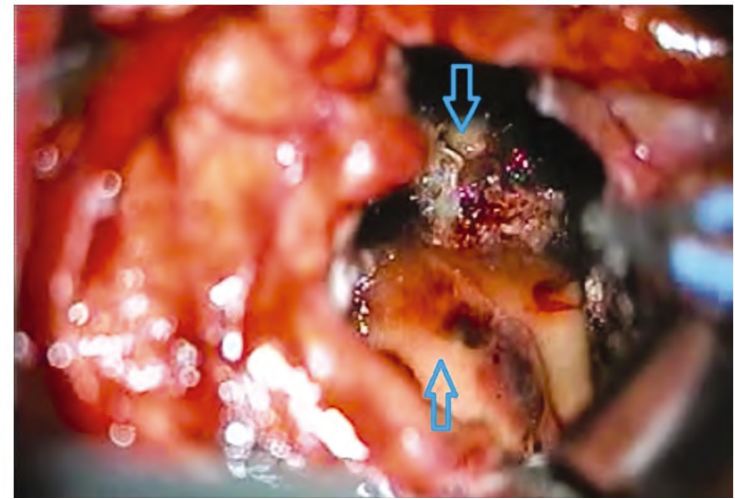

Fig. (3): Microsurgery. The upper arrow points at the tumor being excised after securing the pedicle. The lower arrow points at the ependyma. 
Table (1): Demographic data, clinical findings.

\begin{tabular}{|c|c|c|c|c|c|c|}
\hline & $\begin{array}{c}\text { Age/sex } \\
\text { (years) }\end{array}$ & $\begin{array}{l}\text { Symptoms } \\
\text { of ++ICT }\end{array}$ & Other symptoms (pre) & Symptoms (post) & $\begin{array}{l}\text { Duration } \\
\text { (months) }\end{array}$ & v-p shunt \\
\hline 1 & $3 / \mathrm{F}$ & Yes & Delayed development & Improved & 6 & \\
\hline 2 & $5 / \mathrm{F}$ & No & Rt hemiparesis & Improved & 8 & \\
\hline 3 & $4 / \mathrm{M}$ & Yes & Seizures & Controlled & 10 & \\
\hline 4 & $2 / \mathrm{F}$ & Yes & Lt hemiparesis & Improved & 2 & \\
\hline 5 & $8 / \mathrm{M}$ & Yes & Visual abnormality & Transient weakness & 4 & Rt posterior parietal \\
\hline 6 & $4.5 / \mathrm{M}$ & No & Seizures \& dysphasia & Improved & 8 & \\
\hline 7 & $3 / \mathrm{F}$ & Yes & Seizures & Controlled & 7 & Rt frontal \\
\hline 8 & $2 / \mathrm{M}$ & Yes & Seizures \& 1t fascial palsy & Transient weakness & 10 & \\
\hline 9 & $2.5 / \mathrm{F}$ & Yes & Right hemiparesis & Improved & 2 & \\
\hline 10 & $5.5 / \mathrm{M}$ & No & Visual problem \& seizures & Controlled & 5 & \\
\hline 11 & $7 / \mathrm{F}$ & Yes & Ataxic gait & Improved & 11 & \\
\hline
\end{tabular}

M: Male. F: Female. Pre: Preoperative. Post: Postoperative. VP: Ventriculoperitoneal. Rt: Right. Lt: Left.

Table (2): Location, pathology, size of tumors \& operative findings.

\begin{tabular}{|c|c|c|c|c|c|c|}
\hline & Size & $\begin{array}{c}\text { Blood } \\
\text { transfusion }\end{array}$ & Pathology & Location & Approach & $\begin{array}{l}\text { Postoperative } \\
\text { finding }\end{array}$ \\
\hline 1 & $5 \mathrm{~cm}$ & $150 \mathrm{ml}$ & $\mathrm{CPC}$ & Rt lateral ventricle \& third ventricle & Rt middle frontal gyrus & GTR \\
\hline 2 & $4 \mathrm{~cm}$ & $200 \mathrm{ml}$ & $\begin{array}{l}\text { Atypical } \\
\text { papilloma }\end{array}$ & Lt lateral ventricle & Middle temporal gyrus & GTR \\
\hline 3 & $7 \mathrm{~cm}$ & $300 \mathrm{ml}$ & СРC & Lt occipital & Superior parietal lobule & STR \\
\hline 4 & $4 \mathrm{~cm}$ & $300 \mathrm{ml}$ & CPP & Rt lateral ventricle occipital \& third ventricle & Superior parietal lobule & GTR \\
\hline 5 & $6 \mathrm{~cm}$ & $200 \mathrm{ml}$ & CPP & Rt occipital & Superior parietal lobule & GTR \\
\hline 6 & $7 \mathrm{~cm}$ & $150 \mathrm{ml}$ & CPP & Rt lateral ventricle & Middle temporal gyrus & GTR \\
\hline 7 & $4 \mathrm{~cm}$ & $200 \mathrm{ml}$ & $\mathrm{CPC}$ & Rt parieto-occipital & Superior parietal lobule & GTR \\
\hline 8 & $6 \mathrm{~cm}$ & $300 \mathrm{ml}$ & $\mathrm{CPP}$ & Rt lateral ventricle \& third ventricle & Middle temporal gyrus & STR \\
\hline 9 & $5 \mathrm{~cm}$ & $300 \mathrm{ml}$ & CPP & Lt frontal \& third ventricle & Middle temporal gyrus & GTR \\
\hline 10 & $7 \mathrm{~cm}$ & $300 \mathrm{ml}$ & CPC & Lt lateral ventricle & Superior parietal lobule & GTR \\
\hline 11 & $4 \mathrm{~cm}$ & $200 \mathrm{ml}$ & CPP & Lt occipital & Superior parietal lobule & GTR \\
\hline
\end{tabular}

CPP: Choroid plexus papilloma. CPC: Choroid plexus carcinoma. GTR: Gross total resection. STR: Subtotal resection. Rt: Right. Lt: Left.

\section{Discussion}

In the pediatric age group, the excision of large intraventricular tumors poses a great challenge for neurosurgeons. These tumors usually arise from the deepest region of the brain, close to vital structures and blood vessels. They may even invade the opposite ventricle or all the ventricles. In such patients, hydrocephalus is frequently present which may be attributed to the worsening of the condition. However, ventricular dilatation may help in the surgical approach. A complete assessment of the ventricular anatomy, extension of the neoplasm in relation to eloquent areas and feeding vessels, is mandatory. One should minimize brain retraction to avoid further damage to the already disturbed white matter [12]. Small IVT tumors may be successfully removed via an endoscopic approach, while larger masses are better to be microscopically excised for better bleeding control [3]. We combined the two techniques in our study in the form of endoscope-assisted microsurgery for maximal and safe resection of CPTs.
The small total blood volume in children in association with large vascular tumors as CPTs, forms an additional challenge. There are reports of mortality due to blood loss in the literature $[13,14]$. Thus, attempting to secure the feeding vessels early in the surgery is crucial. Preoperative embolization may be used to prevent catastrophic bleeding [15]. The critical aspect of the surgical approach is to expose the vascular pedicle during the initial stage of the procedure to avoid avulsion of the feeding arteries that are not seen except at the late stage of excision [2]. This may be facilitated by the endoscope early in the surgery [16]. We performed this technique in all our surgeries. This technique also avoids early injury of the vascular pedicle which may become retracted and cause significant bleeding. This may not be feasible in $\mathrm{CPC}$ cases as they invade the ependyma and receive abnormal blood supply with no definite pedicle $[17,18]$

As previously mentioned, intraoperative bleeding can be excessive. This calls for fast and diligent 
hemostasis. The anesthesiologist should be ready for blood transfusion. Every milliliter of blood should be replaced. Hypovolemia caused by intraoperative bleeding is the most common recognizable trigger for anesthesia-related cardiac arrest in children [19]. This may be attributed to the size of the tumor but more importantly its vascularity. In our series, moderate amounts of blood were replaced ranging from 300 to $150 \mathrm{ml}$. We postulate that the early interruption of blood supply assisted by endoscopy helped mitigate the bleeding. In the study by Ogiwara et al., there were two pediatric CPP cases with massive intraoperative bleeding. One of the two surgeries had to be staged due to the life-threatening bleeding in the first surgery. They claim that the pedicle is sometimes not always visible from the beginning of surgery. They did not use endoscope-assistance in their series. The authors advised preoperative embolization, but it is not always available as in our institute [15]. In one of the largest series of pediatric intraventricular tumors by Zuccaro et al., they had a case of mortality in an infant with CPP due to massive intraoperative bleeding. They also did not use endoscope-assistance [12].

After the interruption of blood supply, piecemeal removal by bipolar coagulation and suction under the microscope is usually performed in large IVT [12]. This can be also performed by ultrasonicaspirator but it was not available at our institute at the time of the study [20]. We used large cottonoids to pad the interface formed after the excision of tumor pieces. We gradually increased the size and number of cottonoids to fill the large, formed cavity in order to avoid collapse of the ependymal wall, which might hide tumor parts. Moreover, this allowed temporary hemostasis of the tumor while dealing with other parts, and to avoid hidden bleeding. This hidden bleeding may clot after some time and will not be dislodged during irrigation at the final steps of hemostasis during surgery. These blood clots may cause mass effect or block CSF flow causing hydrocephalus. This was also particularly helpful in some cases of large choroid plexus papilledema, where we should debulk a part of tumor to make a space to reach the pedicle for devascularization.

The Endoscope-assistance is very helpful because we could see hidden angles as in the formerly mentioned cavity which may be collapsed after the tumor shrinks in size. The endoscope could visualize missed tumor parts or large blood clots. It also allowed minimal retraction of the cortex needed to see deep angles of view in the collapsed cavity.
In our study, we had only 2 out of 8 hydrocephalic cases $(25 \%)$ that required permanent CSF diversion. Preoperative shunting was not required in any of our cases. We believe that total excision in benign lesions as in CPP ameliorates the need for CSF diversion. This is similar to the results of Zuccaro et al., where 12 out of 41 hydrocephalic $(29.3 \%)$ required postoperative VP shunts. They stated the same hypothesis that in most cases hydrocephalus is relieved by tumor removal even if it is subtotal. Some authors claim that the high CSF protein content will block a VP shunt before tumor excision and the hydrocephalus is resolved after tumor excision $[\mathbf{1 7 , 2 1 ]}$

In our series, we did not witness mortality. The outcome was improved due to the total excision of benign tumors. This is well documented in the literature, as in surgery of CPP, which is curable with no need for adjuvant therapy $[\mathbf{1 5 , 2 2 ]}$. The radical excision in CPCs improves the survival rate. The addition of chemotherapy or radiotherapy may help in the treatment $[\mathbf{2 3 , 2 4 ]}$. Preoperative neoadjuvant chemotherapy may decrease vascularity during CPC surgery and even improve overall survival. However, it was not used in our series [25]. We had 4 cases of CPC in our series, and they all received postoperative chemotherapy and radiotherapy. One of them showed a residual during follow-up but was stable after 4 years.

\section{Conclusion:}

Endoscope-assisted microsurgery is a safe and efficient method in the management of large IVT in the pediatric population. Dealing with vascular tumors is easier with the help of endoscopy. It permits complete excision which cures benign papillomas and may improve survival in such cases. Permanent CSF diversion may be avoided by total excision.

\section{References}

1- SUH D.Y. and MAPSTONE T.: Pediatric supratentorial intraventricular tumors. Neurosurg Focus [Internet]. Jun, 10 (6): 1-14. Available from: https://thejns.org/ view/journals/neurosurg-focus/ 10/6/foc.2001.10.6.5.xml, 2001.

2- SILVA A.H.D. and AQUILINA K.: Surgical approaches in pediatric neuro-oncology. Cancer Metastasis Rev. [Internet]. Dec., 20; 38 (4): 723-47. Available from: http://link.springer.com/10.1007/s 10555-019-09832-2. 2019.

3- GAAB M.R. and SCHROEDER H.W.: Neuroendoscopic approach to intraventricular lesions. J. Neurosurg [Internet]. Mar., 88 (3): 496-505. Available from: http://www. ncbi.nlm.nih.gov/pubmed/9488304, 1998. 
4- MORITA A. and KELLY P.J.: Resection of Intraventricular Tumors via a Computer-assisted Volumetric Stereotactic Approach. Neurosurgery [Internet]. Jun, 1; 32 (6): 920 7. Available from: https://academic.oup.com/ neurosurgery/article/32/6/920/3771465, 1993.

5- CHOWDHRY S.A. and COHEN A.R.: Intraventricular Neuroendoscopy: Complication Avoidance and Management. World Neurosurg [Internet]. Feb., 79 (2): S15.e1S15.e10. Available from: https://linkinghub.elsevier.com/ retrieve/pii/S1878875012001635, 2013.

6- BIRSKI M., BIRSKA J., PACZKOWSKI D., FURTAK J., RUSINEK M., RUDAS M., et al.: Combination of Neuroendoscopic and Stereotactic Procedures for Total Resection of Colloid Cysts with Favorable Neurological and Cognitive Outcomes. World Neurosurg [Internet]. Jan., 85: 205-14. Available from: https://linkinghub. . elsevier.com/retrieve/pii/S1878875015011249. 2016.

7- CAO H., XIAO Z., ZHANG Y., KWONG T., DANISH S.F., WEINER J., et al.: Dosimetric comparisons of different hypofractionated stereotactic radiotherapy techniques in treating intracranial tumors \& gt; $3 \mathrm{~cm}$ in longest diameter. J Neurosurg [Internet]. Apr., 132 (4): 1024-32. Available from: https://thejns.org/view/journals/jneurosurg/132/4/article-p1024.xml, 2020.

8- FAHLBUSCH R. and HOFMANN B.M.: Surgical management of giant craniopharyngiomas. Acta Neurochir (Wien) [Internet]. Dec., 11; 150 (12): 1213-26. Available from: http://link.springer.com/10.1007/s00701-008-01379, 2008.

9- YUAN J., WANG J.Z., LO S., GRECULA J.C., AMMIRATI M., MONTEBELLO J.F., et al.: Hypofractionation Regimens for Stereotactic Radiotherapy for Large Brain Tumors. Int. J. Radiat. Oncol. [Internet]. Oct., 72 (2): 390-7. Available from: https://linkinghub.elsevier.com /retrieve/pii/S036030160800031X, 2008.

10- PERNECZKY A., FRIES G.: Endoscope-assisted Brain Surgery: Part 1-Evolution, Basic Concept, and Current Technique. Neurosurgery [Internet]. Feb., 1; 42 (2): 21924. Available from: https://academic.oup.com /neurosurgery/article/42/2/219/2856365, 1998.

11- AMMIRATI M. and KSHETTRY V.R.: EndoscopeAssisted Microsurgery. In: Samii's Essentials in Neurosurgery [Internet]. Berlin, Heidelberg: Springer Berlin Heidelberg, p. 77-86. Available from: http://link. springer.com/10.1007/978-3-642-54115-5 8, 2014.

12- ZUCCARO G., SOSA F., CUCCIA V., LUBIENIECKY F. and MONGES J.: Lateral ventricle tumors in children: A series of 54 cases. Childs Nerv. Syst. [Internet]. Nov., 15 (11-12): 774-85. Available from: http://www.ncbi. nlm.nih.gov/pubmed/10603022, 1999.

13- PENCALET P., SAINTE-ROSE C., LELLOUCHTUBIANA A., KALIFA C., BRUNELLE F., SGOUROS S., et al.: Papillomas and carcinomas of the choroid plexus in children. J Neurosurg [Internet]. Mar., 88 (3): 521-8. Available from: http://www.ncbi.nlm.nih.gov/ pubmed/9488307, 1998.

14- DUE-TØNNESSEN B., HELSETH E., SKULLERUD K. and LUNDAR T.: Choroid plexus tumors in children and young adults: Report of 16 consecutive cases. Childs Nerv. Syst. [Internet]. Apr., 17 (4-5): 252-6. Available from: http://www.ncbi.nlm.nih.gov/pubmed/11398945, 2001.
15- OGIWARA H., DIPATRI A.J., ALDEN T.D., BOWMAN R.M. and TOMITA T.: Choroid plexus tumors in pediatric patients. Br J Neurosurg [Internet]. Feb., 4; 26 (1): 327. Available from: http://www.tandfonline.com/ doi/full/10.3109/02688697.2011.601820, 2012.

16- CAPPABIANCA P., CINALLI G., GANGEMI M., BRUNORI A., CAVALLO L.M., de DIVITIIS E., et al.: Application of Neuroendoscopy To Intraventricular Lesions. Neurosurgery [Internet]. Feb., 1; 62 (Suppl 2): SHC57598. Available from: https://academic.oup.com /neurosurgery/article/62/suppl_2/SHC575/2581137, 2008.

17- COATES T.L., HINSHAW D.B., PECKMAN N., THOMPSON J.R., HASSO A.N., HOLSHOUSER B.A., et al.: Pediatric choroid plexus neoplasms: MR, CT, and pathologic correlation. Radiology. Oct., 173 (1): 81-8, 1989.

18- MENON G., NAIR S., BALDAWA S., RAO R., KRISHNAKUMAR K. and GOPALAKRISHNAN C.: Choroid plexus tumors: An institutional series of 25 patients. Neurol. India, 58 (3): 429, 2010.

19- VASSAL O., DESGRANGES F-P., TOSETTI S., BURGAL S., DAILLER F., JAVOUHEY E., et al.: Risk factors for intraoperative allogeneic blood transfusion during craniotomy for brain tumor removal in children. Davidson A, editor. Pediatr Anesth [Internet]. Feb., 26 (2): 199206. Available from: http://doi.wiley.com/10.1111/ pan. 12810, 2016

20- SOOD S., NUNDKUMAR N. and HAM S.D.: Interhemispheric endoscopic resection of large intraventricular and thalamic tumors. J. Neurosurg Pediatr. [Internet]. Jun., 7 (6): 596-9. Available from: https://thejns.org/view/ journals/j-neurosurg-pediatr/7/6/article-p596.xml, 2011.

21- YAN C., XU Y., FENG J., SUN C., ZHANG G., SHI J., et al.: Choroid plexus tumours: Classification, MR imaging findings and pathological correlation. J. Med. Imaging Radiat. Oncol. Apr., 57 (2): 176-83, 2013.

22- TOMITA T., McLONE D.G. and FLANNERY A.M.: Choroid Plexus Papillomas of Neonates, Infants and Children. Pediatr Neurosurg [Internet], 14 (1): 23-30. Available from: https://www.karger.com/Article/FullText/ 120358, 1988.

23- CLAIRE B., PHILIPPE T., ARIELLE L-T., CHANTAL K., ALAIN P-K. and ERIC B.: Choroid Plexus Carcinomas in Childhood: Clinical Features and Prognostic Factors. Neurosurgery [Internet]. Mar., 1; 42 (3): 470-5. Available from: https://academic.oup.com/neurosurgery/article . /42/3/470/2843328, 1998.

24- HOSMANN A., HINKER F., DORFER C., SLAVC I., HABERLER C., DIECKMANN K., et al.: Management of choroid plexus tumors-an institutional experience. Acta Neurochir (Wien) [Internet]. Apr., 19; 161 (4): 745-54. Available from: http://link.springer.com/10.1007/s00701019-03832-5, 2019.

25- SCHNEIDER C., KAMALY-ASL I., RAMASWAMY V., LAFAY-COUSIN L., KULKARNI A.V., RUTKA J.T., et al.: Neoadjuvant chemotherapy reduces blood loss during the resection of pediatric choroid plexus carcinomas. J. Neurosurg Pediatr. [Internet]. Aug., 16 (2): 12633. Available from: https://thejns.org/view/journals/jneurosurg-pediatr/16/2/article-p126.xml, 2015. 


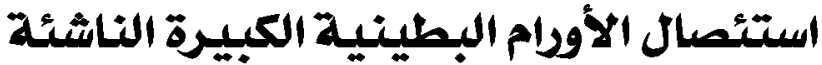

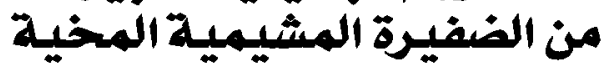

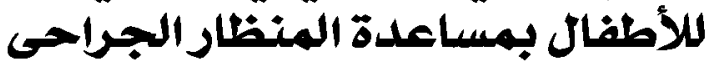

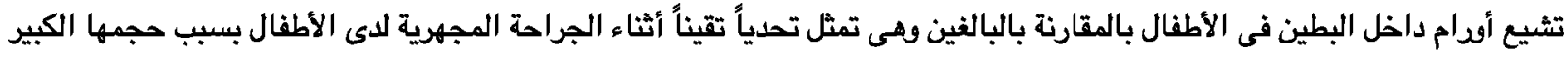

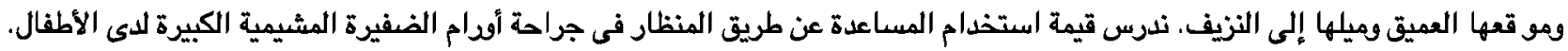

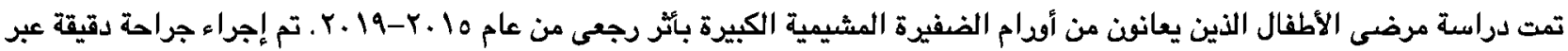

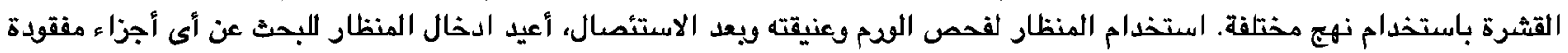
والمساعدة فى وقف النزيف الدموى.

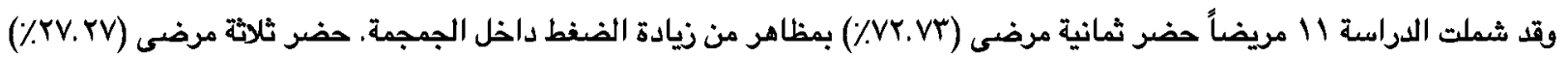

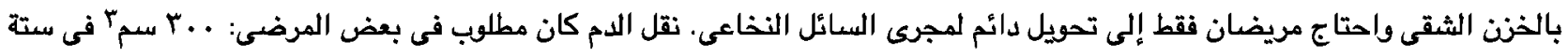

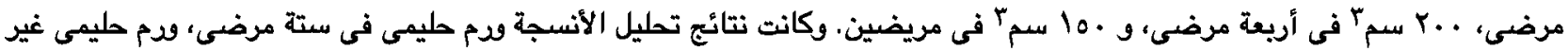

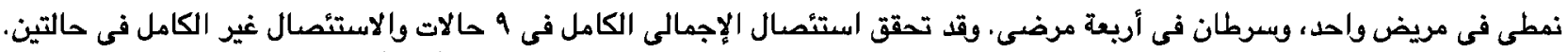

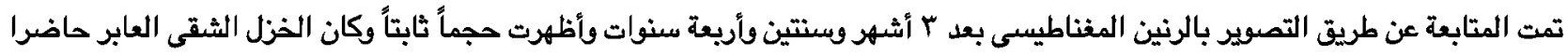

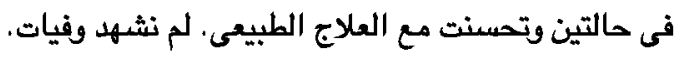

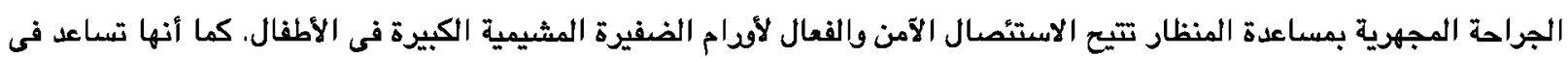

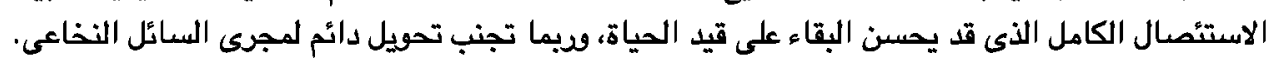

